STANDARDISATION OF RADIOLOGICAL TERMINOLOGY IN PULMONARY DISEASE AND STANDARDISATION OF TECHNIQUE IN CHEST RADIOGRAPHY

From the Joint Tuberculosis Council, the Faculty of Radiologists and the Society of Thoracic Surgeons. Pp. 12. London: H.M.S.O. 1952. $6 d$.

This is a very useful memorandum for clinicians and radiologists. It includes diagrams and the recommended nomenclature for the main bronchi and pulmonary segments.

\section{TEXTBOOK OF CLINICAL PATHOLOGY}

Edited by S. E. Miller, M.D. 4th Edition. Pp. xxvi + ro6o, with 208 illustrations. London: Baillière, Tindall and Cox. 1952. 68s. 6d.

This book aims at giving the practising clinician details only of those techniques that he himself is likely to use, the remainder of the book being concerned with the choice and interpretation of laboratory tests. At least, this is what is claimed for the book in the editor's preface, although it seems very doubtful if many of the tests given in detail would ever be used by any clinician who had not access to a large and well-equipped laboratory. For instance, the haemagglutination inhibition test for the diagnosis of influenza is given in detail, and no less than 63 pages are devoted to a consideration of the blood groups. The different sections of the book are dealt with in a very uneven manner, haematology receiving over 350 pages, while blood chemistry is discussed in 84 pages, the authors of this section having included no technical details at all. The reviewer cannot help wondering whether instructions as to how to estimate blood sugar and blood urea might not be of considerably more value to the clinician than, for instance, descriptions of pneumococcal typing, chick embryo inoculation for the isolation of viruses, or the diagnosis of rabies by mouse inoculation, all of which are given in considerable detail.

In spite of these criticisms, it must be said that the authors have compressed in this book an amazing amount of accurate information. It will be found of considerable value to a wide circle of readers, although its usefulness could be considerably enhanced in a later edition by an extension of the section on biochemistry. The latter should include some information on faecal chemistry, particularly on faecal fats and the demonstration of occult blood, and also details of the simpler methods of estimating some of the chemical constituents of the blood.

\section{LUMBAR DISC LESIONS: PATHOGENESIS AND TREATMENT OF LOW BACK PAIN AND SCIATICA}

By J. R. Armstrong, M.D., M.Ch., F.R.C.S. Pp. viii +228 , with 77 illustrations, 21 in colour. Edinburgh: E. \& S. Livingstone. 1952. $42 \mathrm{~s}$.

This book gives a good, brief account of current teaching on the subject of the diagnosis and treat- ment of low back pain and sciatica. Where the author gives his own views, as, for instance, in soms of the sections dealing with the mechanism of the production of pain, he is careful to state that he is. doing so. The book is, on the whole, very we illustrated, although the lower part of Plate rob is so blurred that it is difficult to see the spondylolise thesis and Plates $12 a$ and $b$ are perhaps a little misleading because, although they show changes due to ankylosing spondylitis, they do not show thg advanced changes in the lumbar spine which th caption would suggest.

These are minor faults and do not seriousl $\vec{P}$ detract from the merits of a book which fills a reat need for a short and authoritative account of this difficult subject. It can be strongly recommendes to anyone requiring a guide to the diagnosis ang treatment of sciatic and low back pain.

\section{THE CLINICAL APPLICATION OF ANTIBIOTICS}

By M. E. Florey, M.D. Pp. xiii +730 , with I 1 宛 illustrations. London: Geoffrey Cumberlege? 1952. £4 4s.

This is essentially a reference book. The Oxford team under Sir Howard W. Florey have alread\$ provided the laboratory workers with a symposiuns on the experimental aspects of the antibiotics. The present work is intended to meet the needs of the clinician using penicillin and is the first of two, the second of which will deal with the other antibiokics in the same way.

There have been so many books dealing with this subject already that it is reasonable to conside whether another is justified. The time has nov日 come when the uses of penicillin can be fairlo assessed and when it is most unlikely that new clinical applications will be found. Even the laboratory work which has been stimulated by the discovery of the antibiotics is now tending to follow lines diverging from the interests of the clinician an is leading to fundamental studies in bacteriat metabolism and genetics. Previous publications. have mainly been in the nature of interim reportsis but this should find a fairly permanent place on the library shelves.

The book would be worth while for the docu mentation alone; any references that might reasono ably be required are here and the tables of data are most valuable. In the text I was particularly im pressed by the attention given to the failures of penicillin. This should help to prevent wastage of time and drugs when an unusual condition iš encountered.

It is difficult to find any faults in this book. I I is true that the chapter on administration could be simplified for present use, but the detaile ob description of methods that have been used in the्छ past will evoke useful memories of the days when $\stackrel{\text { s }}{+}$ twe ntieth of the present scales of dosage gave as excellent results.

W.H.H.

,

.

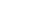

